ORIGINAL RESEARCH ARTICLE

pISSN 09763325 | eISSN 22296816

Open 2 Access Article (CC BY-SA)

www.njcmindia.org

DOI: $10.55489 / \mathrm{njcm} 1322022161$

\title{
Prevalence of Obesity and Overweight and Its Correlates among 20-40 Year Old Population in an Urban Area in Southern India
}

\author{
Bhagyalaxmi Sidenur'1, Gowrishankar², Sudharani Mupparapu ${ }^{3}$
}

\begin{abstract}
${ }^{1}$ Assistant Professor, Department of Community medicine, Basaveshwara medical college and Hospital, Chitradurga 2Professor, Department of Community medicine, S.Nijalingappa medical college, hospital and research centre, Bagalkot ${ }^{3}$ Associate professor, Department of Community medicine, Basaveshwara medical college and Hospital, Chitradurga
\end{abstract}

\begin{abstract}
Introduction: Obesity has reached epidemic proportions globally, with at least 2.8 million people dying each year as a result of consequences of overweight or obesity. The study was conducted to estimate the prevalence of Overweight and obesity among 20-40 years old residing in an urban area in North Karnataka and to study the risk factors affecting overweight and obesity.

Methods: A Cross Sectional Study was done among adults aged 20-40 years in urban field practice area in North Karnataka in 2017-18. The sample size was calculated to be 207. Selection of study subjects was done using systematic random sampling. Data regarding socio-demographic profile and anthropometric measurements were collected and BMI calculated.

Results: The prevalence of overweight was $45.9 \%$ and obesity was $11.1 \%$. Females had more prevalence of overweight (46.8\%) and obesity (13.8\%) as compared to males. overweight was more in sedentary workers $(50 \%)$.There was a high prevalence of obesity among participants with mixed $\operatorname{diet}(82.6 \%)$ and $63.1 \%$ of participants eating junk food were overweight and $69.5 \%$ were obese. The prevalence of overweight was more among participants with class IV socioeconomic status $(45.3 \%)$ followed by class III (31.6\%).
\end{abstract}

Conclusion: There is a growing prevalence of overweight and obesity in urban areas that calls for an urgent need to prevent the further consequences and decrease the burden.

Keywords: Overweight, Obesity, Hypertension, Urban area

\section{INTRODUCTION}

Obesity has reached epidemic proportions worldwide, with at least 2.8 million people dying each year from the consequences of being overweight or obese. ${ }^{1}$ In 2016, over 1.9 billion adults aged 18 and above were overweight. Of these over 650 million were obese ${ }^{2}$. In India, $31.3 \%$ of women and $26 \%$ of men in urban areas are overweight or obese and in Karnataka, $37.1 \%$ of women and $39.4 \%$ of men in urban areas are overweight or obese. ${ }^{3}$
While obesity has been generally associated with genetic predispositions, the development of such epidemics around the world suggests that environmental risk factors are also equally responsible for its prevalence. ${ }^{4}$ People in developed and developing countries have started consuming more energydense foods and engaging in less physical activity. This has led to overweight and obesity epidemics around the world. ${ }^{5}$ The World Health Organization (WHO) has also reported that susceptible people have often been exposed to a lifestyle characterized by less physical activity, abundant availability of How to cite this article: Sidenur B, Gowrishankar, Mupparapu S. Prevalence of Obesity and Overweight and Its Correlates among 20-
$\begin{aligned} & 40 \text { Year Old Population in an Urban Area in Southern India. Natl J Community Med 2022;13(2):114-119. DOI: } \\ & 10.55489 / \text { nicm1322022161 }\end{aligned}$

Financial Support: None declared Conflict of Interest: None declared
Date of Submission: 29-12-2021

Date of Acceptance: 24-02-2022

Date of Publication: 28-02-2022

Correspondence: Dr. Bhagyalaxmi Sidenur (Email: bhagyasidenur@gmail.com)

Copy Right: The Journal retains the copyrights of this article. However, reproduction is permissible with due acknowledgement of the source. 
high-energy, high-fat and tasty foods, and inappropriate eating habits. ${ }^{6}$

Routine monitoring of nutritional status through collection of anthropometric data is a simple, inexpensive approach that can be easily applied to large number of people. The body mass index (weight (kg)/height (m)2) is a useful index of relative weight that can be applied to define obesity and can be used to assess individual and community nutritional status. $^{7}$

India which is typically known for its high prevalence of undernutrition, a considerable prevalence of overweight and obesity now co-exists among the population. ${ }^{8}$ If untreated, obesity is accountable for a large proportion of non-communicable diseases (NCDs) including cardiovascular disease, diabetes, liver disease and cancer. Public Distribution System (PDS) supplies mainly rice. The staple grains in Northern Karnataka have always been jowar, bajra and wheat. Providing rice can help prevent hunger but it forces poor families to change their diets, and replace these local grains, which are higher in protein and fiber and lower in glycemic load, with rice. PDS covered some of their basic needs with rice and pulses and will therefore use their income for other purchases like calorie dense inexpensive unhealthy items which can lead to a rise in overweight and obesity among low socioeconomic status ${ }^{9}$.

We have undertaken this study in the urban field practice area of Bagalkot city which was affected by backwater of irrigation dam. Hence, it has seen large changes in sociodemographic profile. So, there is need to know self-care activity adherence among the population so that risk factors can be reduced and make them adhere to diet changes and weight management. Prevention, detection and management of obesity in the age group of 20-40 years are necessary to halt the natural history of the diseases and delay complications like Diabetes, hypertension, stroke and cancer. Hence, the current study was undertaken to know the prevalence of overweight and obesity in the urban field practice area among 20-40 year old and to know the risk factors associated with it.

\section{MATERIALS AND METHODS}

The present cross sectional study was undertaken in the urban field practice area of a medical college in the year 2017-18. According to a study done in North East India ,the prevalence of overweight was $32.5 \%{ }^{8}$ So, desired sample was calculated using the formula $4 \mathrm{pq} / \mathrm{l}^{2} \mathrm{p}=32.5 \%$ and allowable error of $10 \%$ of $\mathrm{p}$. Sample size was calculated to be 207.

Age group of 20-40 years in the study population and residents of the study area for more than 6 months were included in the study and pregnant women and seriously ill patients were excluded from the study. Informed consent was taken from the participants and Study protocol was approved by the Institutional
Ethical committee, S N Medical College, Bagalkot with Ref. File No: SNMC/IECHSR/2015-16/A-43/1.1

Selection of study subjects was done using systematic random sampling. Number of families in UHTC $\operatorname{area(n):~2721.Sample~size~is~} 207 . \mathrm{K}=$ No of families / sample size $=13$, sampling interval. The first house was selected at random by lottery method by choosing any number between 1 and13.Thereafter, the other subjects were included by adding every 13th house consecutively starting from the first house till the required sample size was fulfilled.

Predesigned, pre-tested, semi-structured questionnaire was devised to collect information pertaining to the following criteria. Data regarding sociodemographic profile and anthropometric measurements - height, weight, and waist-hip circumference was collected. Body weight was measured (to the nearest $0.5 \mathrm{~kg}$ ) with the subject standing motionless on the weighing scale, the feet spread $15 \mathrm{~cm}$ apart, and the weight is equally distributed on each leg. Subjects were made to remove their footwear and heavy clothing while their weight was being measured. Height was measured (to the nearest $0.5 \mathrm{~cm}$ ) with the subject in an erect position against a vertical surface, with the head positioned so that the top of the external auditory meatus was in level with the inferior margin of the bony orbit. Waist circumference was measured at the approximate midpoint between the lower margin of the last palpable rib and the top of the iliac crest and the subject stood with arms at the sides, feet positioned close together, and weight evenly distributed across the feet. Hip circumference is the maximum circumference in the horizontal plane measured over the buttocks.

Waist hip ratio is the ratio of waist circumference to the hip circumference less than 0.80 in females and less than 0.90 in males is considered normal for South East Asian region.

Modified BG Prasad's classification was used for assessing socio-economic status with consumer price index of January 2016 which is $269 .{ }^{19}$

\begin{tabular}{lll}
\hline $\begin{array}{l}\text { Social } \\
\text { Class }\end{array}$ & \multicolumn{2}{c}{ Per capita Family Income in Rupees } \\
Prasad (1961) & Updated as per Jan 20166 \\
\hline I & 100 and above & 6140 and above \\
II & $50-99$ & $3070-6139$ \\
III & $30-49$ & $1842-3069$ \\
IV & $15-29$ & $921-1841$ \\
V & Below 15 & 920 and below \\
\hline
\end{tabular}

BODY MASS INDEX (BMI): BMI was classified according to WHO Asian classification. ${ }^{10}$ It was calculated based on the formula - Weight (Kg)/Height (m2).

\begin{tabular}{ll}
\hline Weight Status Category & BMI \\
\hline Underweight & $<18.5$ \\
Normal & $18.5-22.9$ \\
Over weight & $23-24.99$ \\
Pre-obese & $25-29.99$ \\
Obese class 1 & $30-40$ \\
Obese class 2 & $40.1-50$ \\
Obese class 3 & $>50$ \\
\hline
\end{tabular}




\section{STATISTICS}

Data was entered in Microsoft Excel 2010 spread sheet, and subsequently it was analyzed using SPSS (trial version 20) and Open Epi software. Descriptive statistics (mean and percentages) wherever necessary were employed. The various factors and their association with hypertension were studied using Chi square test as applicable. $P$ value of $<0.05$ was considered statistically significant and $<0.001$ as highly significant.

\section{RESULTS}

Out of 207 study participants, 9.7\% were underweight and $33.3 \%$ participants had normal BMI and overweight were $45.9 \%$ and obesity was $11.1 \%$.

Females had more prevalence of overweight (46.8\%) and obesity (13.8\%) as compared to males (overweight- $44.9 \%$, obesity $-8.2 \%$ ). Waist-hip ratio was higher in women i.e $40.6 \%$ as compared to men (31.9\%).The prevalence of overweight was observed to be higher among 30-34 years (64.3\%) and obesity was higher among 35-40 years (19.5\%) and the association was statistically significant $(p<0.001)$. The scatter diagram of age and BMI shows for every unit change of BMI, age changes by 0.19 units which are significantly correlated with $\mathrm{p}$ value of 0.031 .(Graph 1)

In our study there were total $89(\%)$ people who were normal by their BMI, 95(\%) were overweight and $23(\%)$ were obese. Among normal study partici- pants $45(50.6 \%)$ were normo-tensives, $43(48.3 \%)$ had pre-hypertension with respect to SBP whereas when DBP was considered,50(56.2\%) had prehypertension. Among overweight participants $59(62.1 \%)$ had pre-hypertension with respect to SBP but at the same time $51(53.7 \%)$ were prehypertensives with respect to DBP. Among obese participants $14(60.9 \%)$ and $12(52.2 \%)$ were prehypertensives with respect to SBP and DBP respectively and it was statistically significant (0.001). (Table 1)

\section{Graph 1: Association of age with overweight and} obesity

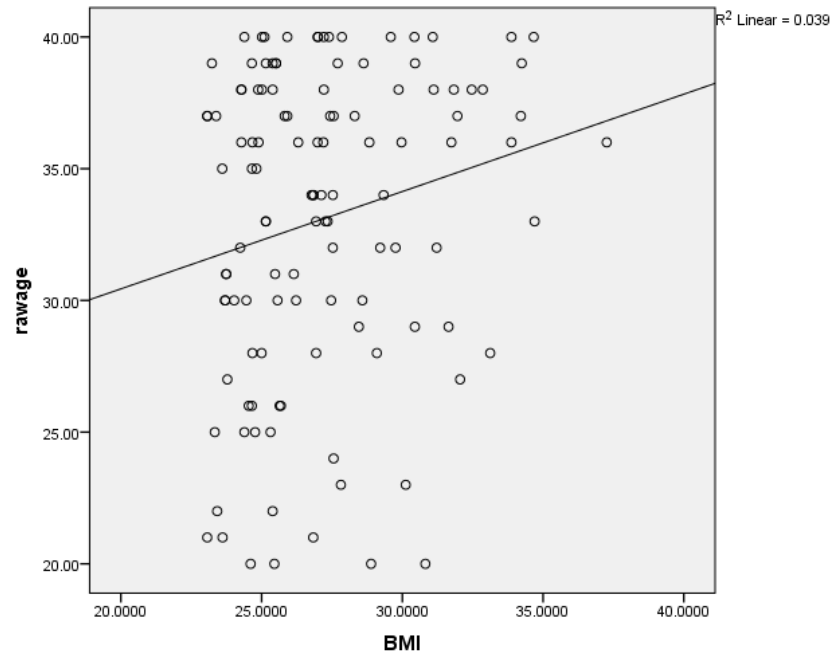

Pearson correlation- 0.19 , p value -0.03

Table 1: Association of socio-demographic characteristics with overweight and obesity

\begin{tabular}{|c|c|c|c|c|}
\hline Factor & Normal (N=89) (\%) & Overweight (N=95) (\%) & Obesity (N=23) (\%) & $X^{2}$ (p value) \\
\hline \multicolumn{5}{|c|}{ Systolic blood pressure } \\
\hline Normal & $45(50.6)$ & $27(28.4)$ & $05(21.7)$ & \multirow[t]{3}{*}{$18.44(0.001)$} \\
\hline Pre hypertension & $43(48.3)$ & $59(62.1)$ & $14(60.9)$ & \\
\hline Stage 1 HTN & $01(1.1)$ & $09(9.5)$ & $04(17.4)$ & \\
\hline \multicolumn{5}{|c|}{ Diastolic blood pressure } \\
\hline Normal & $31(34.8)$ & $22(23.2)$ & $03(13)$ & \multirow{4}{*}{$18.09(0.006)$} \\
\hline Pre hypertension & $50(56.2)$ & $51(53.7)$ & $12(52.2)$ & \\
\hline Stage 1 HTN & $05(5.6)$ & $21(22.1)$ & $06(26.1)$ & \\
\hline Stage 2 HTN & $03(3.4)$ & $01(1.1)$ & $02(8.7)$ & \\
\hline \multicolumn{5}{|l|}{ Type of diet } \\
\hline Vegetarian & $45(50.5)$ & $31(32.6)$ & $4(17.4)$ & \multirow{2}{*}{$11.1(0.003)$} \\
\hline Mixed diet & $44(49.4)$ & $64(67.3)$ & $19(82.6)$ & \\
\hline \multicolumn{5}{|c|}{ Intake of junk food (fast food) } \\
\hline Consuming & $30(33.7)$ & $60(63.1)$ & $16(69.5)$ & \multirow[t]{2}{*}{$19.4(<0.001)$} \\
\hline Not consuming & $59(66.2)$ & $35(36.8)$ & $7(30.4)$ & \\
\hline \multicolumn{5}{|c|}{ Socioeconomic status } \\
\hline Class I & $4(4.5)$ & $3(3.2)$ & - & \multirow{5}{*}{$13.1(0.11)$} \\
\hline Class II & $5(5.6)$ & $7(7.4)$ & $1(4.3)$ & \\
\hline Class III & $22(24.7)$ & $30(31.6)$ & $11(47.8)$ & \\
\hline Class IV & $32(36)$ & $43(45.3)$ & $6(26.1)$ & \\
\hline Class V & $26(29.2)$ & $12(12.6)$ & 5 (21.7) & \\
\hline \multicolumn{5}{|l|}{ Nature of work } \\
\hline Sedentary & $24(27)$ & $47(50)$ & $12(52.2)$ & \multirow[t]{3}{*}{$12.3(0.01)$} \\
\hline Moderate & $51(57.3)$ & $34(36.2)$ & $9(39.1)$ & \\
\hline Heavy & $14(15.7)$ & $13(13.8)$ & $2(8.7)$ & \\
\hline
\end{tabular}


Table 2: Results of binary logistic regression analysis of independent risk factors with overweight and obesity

\begin{tabular}{llll}
\hline Risk factors & Odds ratio (95\% CI) & Adjusted odds ratio(95\% CI) & p value \\
\hline Hypertension & 1 & 1 & 0.4 \\
$\quad$ Normal & $1.9(0.40-9.6)$ & $1.3(0.26-7.5)$ & 0.31 \\
$\quad$ Pre-hypertension & $2.7(0.43-13.6)$ & $2.1(0.33-13.3)$ & 0.04 \\
$\quad$ Stage 1 & $17(1.0-18.3)$ & $4.8(0.22-10.1)$ & 0.07 \\
$\quad$ Stage 2 & $3.72(0.78-17.7)$ & $63(0.846-47.6)$ & 0.008 \\
$\quad$ Nature of work & $9.9(1.9-52.2)$ & $9.9(2.21-78.8)$ & \\
$\quad$ Sedentary & 1 & 1 & 0.04 \\
$\quad$ Moderate & 1 & 1 & 0.02 \\
$\quad$ Feavy & $2.7(0.87-8.8)$ & $4.3(0.89-20.6)$ & \\
$\quad$ Vegetarian & & & \\
$\quad$ Mixed diet & $1.3(0.52-3.32)$ & $2.6(0.68-14.7)$ & \\
$\quad$ Consuming & 1 & 1 & \\
$\quad$ Not consuming & & & \\
\hline * Binary logistic regression model & & & \\
\end{tabular}

When diet was considered to compare with obesity, it was found that majority i.e 64(67.3\%) and $19(82.6 \%)$ who consume mixed diet were overweight and obese respectively. This finding was statistically significant with $\mathrm{p}$ value of 0.003 . Intake of junk food was also significantly associated with overweight and obesity ( $p<0.001) .60$ (63.1\%) who consume junk food were overweight and 16(69.5\%) were obese. (Table 1)

Unemployed subjects had more percentage of overweight $(49.4 \%)$ followed by unskilled workers $(33.3 \%)$ and skilled workers (22.2\%). Obesity was observed more in unemployed and skilled workers $(11.1 \%)$ followed by unskilled $(6.7 \%)$. The prevalence of overweight (48.6\%) and obesity (12.1\%) was high in married population as compared to unmarried.

Socio-economic status and BMI were compared in our study. It was seen that majority belonged to class III and Class IV. Among overweight study participants $43(45.3 \%)$ belonged to Class IV and among obese $11(47.8 \%)$ belonged to class III. Based on the nature of work, overweight (50\%) was observed to be more in sedentary workers followed by moderate workers $(36.2 \%)$ and obesity was more in sedentary workers (52.2\%) followed by moderate workers(39.1\%) and the association was statistically significant $(\mathrm{p}<0.05)$. (Table 1)

Subjects not performing physical activity had 3.4 times [OR- 3.4(95\% CI 0.7-16.4) P- 0.12] higher risk of being overweight and obese than participants who were performing physical activity and it was not significant.

Odds of being overweight and obese was 2 times [OR- 2.7 (95\% CI 043-13.6) P-0.31] more in stage 1 hypertension and 17 times [OR- 17 (95\% CI 1.2-18.3 ) P-0.04] in stage 2 hypertension compared to subjects having blood pressure within normal limits and it was significant.
Subjects having stress had 2 times more chances of being overweight and obese [OR-2.1 (95\% CI 2.627.59) P-0.01] compared to subjects not having stress and it was statistically significant.

Sedentary workers had 6 times [OR-6.3 (95\% CI 0.846- 47.6) P-0.07] and moderate workers had 10 times [OR-9.9(95\% CI 2.21-78.8 )P-0.008] higher risk of being overweight and obese than heavy workers and it was statistically significant.

It was observed that there was 4.3 times higher risk of being overweight and obese in the participants consuming mixed diet compared to vegetarian diet[ OR-4.3 (95\% CI 0.89 -20.6) P-0.04] and it was statistically significant.

Subjects consuming junk food had 2.6 times more chances of being overweight and obese [OR-2.6 ( 95\% CI 0.68-14.7) P- 0.02] than not consuming and it was statistically significant. (Table 2)

\section{DISCUSSION}

In the present study, the prevalence of overweight among $20-40$ years old was $45.9 \%$ and obesity was $11.1 \%$. A similar finding was noted in a study done in an urban area of Pune, Maharashtra with prevalence of overweight-obesity being $43 \% .{ }^{11}$ In a study done in an urban area of Assam, the prevalence of overweight was $32.5 \%$ and obesity was $10.7 \% .^{8}$ This indicates the gravity of the situation, even in urban slum areas.

In our study, females had more prevalence of overweight (46.8\%) and obesity (13.8\%) as compared to males. In a study done in an urban field practice area of a Medical college in Hyderabad, 31.3\% females had overweight-obesity which is less compared to the present study. ${ }^{14}$ As per NFHS 5, the prevalence of overweight -obesity (BMI $\geq 25.0 \mathrm{~kg} / \mathrm{m}^{2}$ ) was $37.1 \%$ which is also less compared to our study. ${ }^{3}$ This variation could be due to sedentary lifestyle and lack of 
awareness about the consequences of obesity among females in our study population.

In the present study, prevalence of overweight was observed to be higher among 30-34 years (64.3\%) followed by $35-40$ years (57.1\%) and obesity was higher among 35-40 years (19.5\%) followed by 2529 years (8.9\%). In a study done in Theni district, Tamilnadu, the prevalence of overweight among 3050 years was $23.3 \% .^{12}$ This finding is lower than the present study and prevalence of obesity was 33.5\% which was much higher than this study. In another study done in North India, there was increased prevalence of overweight $(16.3 \%)$ and obesity was $5.1 \%$ which is consistent with our study. ${ }^{13}$ The difference could be due to different socio demographic profile and nutritional factors.

The study reported that unemployed subjects had more percentage of overweight (49.4\%) and obesity (11.1\%). In a study done in Theni district, Tamilnadu, the prevalence of overweight (36.4\%) and obesity (45.5\%) was higher among unemployed subjects which is consistent with our study but obesity was much higher compared to our study. ${ }^{12}$ This may be due to a stress and sedentary lifestyle following unemployment and also due to a cheaper high carbohydrate diet.

In the present study, the prevalence of overweight (48.6\%) and obesity (12.1\%) was high in married population as compared to unmarried. A study done at Theni district, Tamilnadu shows higher prevalence of overweight $(24.4 \%)$ and obesity $(30.3 \%)$ among married. ${ }^{12}$ Another study done in an urban field practice area of a Medical college in Hyderabad also shows higher percentage overweight-obesity (39.8\%) among married population which is similar to our study. ${ }^{14}$ This could be due to lack of physical activity and stress and poor quality diet.

In this study, Hypertension was observed in 58.3\% who were overweight and $19.4 \%$ who were obese. $43(48.3 \%)$ had pre-hypertension with respect to SBP where as when DBP was considered, 50(56.2\%) had pre-hypertension. Among overweight participants $59(62.1 \%)$ had pre-hypertension with respect to SBP but at the same time $51(53.7 \%)$ were prehypertensives with respect to DBP. Among obese participants $14(60.9 \%)$ and $12(52.2 \%)$ were prehypertensives with respect to SBP and DBP respectively. A study done in an urban field practice area of a medical college, Pune shows that out of 22 obese subjects $63.6 \%$ were hypertensive and $36.3 \%$ were normotensive. ${ }^{11}$ In another study done at Gandhinagar, Out of 29 obese subjects, $62 \%$ were hypertensive and $37.9 \%$ were normotensive which shows hypertension is seen more among obese. ${ }^{17}$ This could be attributed to obesity-related hypertension which is a multifactorial and polygenic trait The multiple potential mechanisms contribute to the development of higher Blood pressure in obese individuals including hyperinsulinemia, activation of the reninangiotensin-aldosterone system, abnormal levels of adipokines like leptin, and altered spectrum of cytokines functioning at the vascular endothelial level. ${ }^{18}$

When diet was considered to compare with obesity, it was found that majority i.e 64(67.3\%) and $19(82.6 \%)$ who consume mixed diet were overweight and obese respectively .A study done in Mumbai, Maharashtra reported that type of diet and obesity was not associated. ${ }^{14}$ Similar result was seen in a study done in Gujarat which reported overweight people were more in the group consuming a mixed diet $(25.1 \%)$ than those who were strictly vegetarian. ${ }^{15}$

Intake of junk food was also significantly associated with overweight and obesity $(\mathrm{p}<0.001) .60$ (63.1\%) who consume junk food were overweight and $16(69.5 \%)$ were obese. A study done in Gujarat reported overweight/obesity people was more in the group consuming junk food (31.5\%). ${ }^{15}$ Another study done in Tamilnadu also reported overweight /obesity was more among people eating junk food $(64.7 \%) .^{12}$ This difference could be due to factors that varies from genetic to environmental factors like increased food consumption and changes in food habits.

It was seen that majority belonged to class III and Class IV. Among overweight study participants $43(45.3 \%)$ belonged to Class IV and among obese $11(47.8 \%)$ belonged to class III.A study done in urban area of North India, shows the highest prevalence of overweight/obesity in people with high socioeconomic status. ${ }^{16}$ This difference could be due to availability of calorie-dense food, and shifts in occupational patterns from agriculture to employment that requires less strenuous work. This could also be attributed to India's public distribution system which provides free rice in large quantities to households living in poverty. These supplies are supposed to prevent hunger but may also change the types and quantities of foods consumed such as free rice may replace other grains, such as millets which are not free and thus have to be purchased. The PDS may also increase the food choices available to people under low socioeconomic status depending upon the residential area by providing for some of their most basic food needs and poor families may use their limited income to purchase other items, like nonperishable high calorie food items which satisfy hunger for a relatively low price. ${ }^{9}$

\section{CONCLUSION AND RECOMMENDATIONS}

The present study revealed the prevalence of overweight (45.9\%) and obesity (11.1\%) is high in the 20-40 years old age group. With increasing levels of modernization the levels are only likely to increase. Most factors in the study are modifiable like sedentary lifestyle, lack of exercise and eating junk food which can be changed. This can be a potential intervention point wherein people are alerted to their overweight status early when weight reduction may 
be easier. Measures for lifestyle change should begin early as they are still young and can easily inculcate a healthy lifestyle which includes regular physical activity (exercise for at least 30 minutes each day ) low calorie balanced diet, high protein diet. Mass screening of the population should be carried out regularly to detect overweight and obesity so that interventions to prevent and control can be infinitely added. Conducting camps in urban slum areas and making population aware about obesity and its causes and consequences. Primordial prevention can play a very crucial role in preventing obesity. As the prevalence of obesity is increasing, it is an absolute necessity that there is a National programme for preventing and control of overweight and obesity .The programme should promote prevention and control of obesity through behaviour and lifestyle changes. Routine detection of at risk persons and community education focussing on intake of protein rich diet with fruits and vegetables, increased physical activity and stress management.

\section{ACKNOWLEDGEMENT}

We are thankful to the participants for their cooperation in the study.

\section{REFERENCES}

1. Facts on obesity. Available at:https://www.who.int/newsroom/facts-in-pictures/detail/6-facts-on-obesity. Accessed $12^{\text {th }}$ October

2. Obesity and Overweight factsheet. Available at https://www.who.int/news-room/fact-sheets/detail/obesityand-overweight. Accessed $12^{\text {th }}$ October

3. National family health survey-5 (NFHS 5). Karnataka state facts sheet. Ministry of health and family welfare,2019-20;1-7. (Available at: http://rchiips.org/nfhs/factsheet_NFHS-5.s html)

4. Sen J, Mondal N, Dutta S. Factors affecting overweight and obesity among urban adults: a cross-sectional study. Epidemiology, Biostatistics and Public Health. 2013 Jan 17;10(1). (Available at : https://www.semanticscholar.org/paper/ Factors -affecting-overweight-and-obesity-among-a-Sen Mondal/23bd6bff52ea2a9382f310a5b941bd36017b133c)

5. World Health Organization (WHO). The World HealthReport. Reducing risks, promoting health life. Geneva: World Health Organization, 2002. (Available at : https://apps.who.int/iris /bitstream/handle/10665/42510/WHR_2002.pdf)

6. World Health Organization (WHO). Obesity: preventing and managing the global epidemic. WHO Obesity Technical Report Series, No. 894. Geneva: World Health Organization, 2000. (Available at: https://apps.who.int/iris/handle/10665/423 30)

7. Shukla HC, Gupta PC, Mehta HC, Hébert JR. Descriptive epidemiology of body mass index of an urban adult population in western India. Journal of Epidemiology \& Community Health. 2002 Nov 1;56(11):876-80. (Available at: https://pubmed .ncbi.nlm.nih.gov/12388581/)
8. Rengma MS, Sen J, Mondal N. Socio-economic, demographic and lifestyle determinants of overweight and obesity among adults of Northeast India. Ethiopian journal of health sciences. 2015 Jul 27;25(3):199-208. (Available at : https://www.ncbi .nlm.nih.gov/pmc/articles/PMC4650874/)

9. Cunningham SA, Shaikh NI, Datar A, Chernishkin AE, Patil SS. Food subsidies, nutrition transition, and dietary patterns in a remote Indian district. Global Food Security. 2021 Jun 1;29:100506. (Available at : https://pubag.nal.usda.gov/ cata$\log / 7301794)$

10. WHO. Consultation WE. Appropriate body-mass index for Asian populations and its implications for policy and intervention strategies. Lancet (London, England). 2004 Jan 10;363(9403):157-63. (Available at: https://pubmed. ncbi.nlm.nih.gov/14726171/)

11. Gothankar JS, Patil RS. Prevalence of obesity and its associated co morbidities amongst adults. Natl J Community Med. 2011 Jul;2(2):221-4. (Available at : https://www.njcmindia.org /home/abstrct/127/)

12. Murugan R, Therese M. Prevalence and associated factors of obesity among adults in Tamilnadu state, South india. International Journal of Current Research. 2016 Sep 8(09) :38193200. (Available at :https://www.researchgate.net/publication /313530022_PREVALENCE_AND_ASSOCIATED_FACTORS_OF OBESITY_AMONG_ADULTS_IN_TAMIL_NADU_STATESOUTH_I NDIA)

13. Masoodi SR, Wani AA, Wani AI, Bashir MI, Laway BA, Zargar AH. Prevalence of overweight and obesity in young adults aged 20-40 years in North India (Kashmir Valley). Diabetes research and clinical practice. 2010 Jan 1;87(1):e4-6. (Available at : https://www.researchgate.net/publication/ 40683407 _Prevalence_of_overweight_and_obesity_in_young adults_aged_20 40_years_in_North_India_Kashmir_Valley/link /5c7055a6a6fdcc4715941b6c/download)

14. Rao BB, Junapudi SS. A comparative study of prevalence of overweight and obesity among urban, and rural population of South India. Int J Commun Med Public Health. 2019 Mar;6:1091-5.

15. Vadera BN, Yadav SB, Yadav BS et al. Study on obesity and Influence of dietary factors on the weight status of an adult population in Jamnagar city of Gujarat: A cross-sectional analytical study. Indian journal of community medicine: official publication of Indian Association of Preventive \& Social Medicine. 2010 0ct;35(4):482. (Avaialble at ; https://www.ncbi. nlm.nih.gov/pmc/articles/PMC3026124/)

16. Girdhar S, Sharma S, Chaudhary A, Bansal P, Satija M. An epidemiological study of overweight and obesity among women in an urban area of North India. Indian journal of community medicine: official publication of Indian Association of Preventive \& Social Medicine. 2016 Apr;41(2):154. (Available at ; https://www.ncbi.nlm.nih.gov/pmc/articles/PMC4799640/)

17. Parikh A. Study of prevalence of obesity and associated comorbidities among adults of Gandhinagar, Gujarat. IAIM, 2014; 1(1):12-7. Available at : https://pubhtml5.com/asoz/bzpu /basic

18. Vaněčková I, Maletínská L, Behuliak M, Nagelová V, Zicha J, Kuneš J. Obesity-related hypertension: possible pathophysiological mechanisms. Journal of Endocrinology. 2014 ;223(3):63-78. Available at : https://pubmed.ncbi.nlm.nih.gov /25385879/

19. Modified B.G.Prasad classification. Available from: URL :http://prasadscaleupdate.weebly.com 